\title{
Correction
}

\section{Correction: Risk Factors and Spatial Distribution of Schistosoma mansoni Infection among Primary School Children in Mbita District, Western Kenya}

\section{The PLOS Neglected Tropical Diseases Staff}

There is an error in the Acknowledgements section. Kentaro Kato did not contribute to this study. The correct Acknowledgements should read:

The authors appreciate teachers, parents and schoolchildren who participated in this study. We are grateful for the support offered by Mbita District hospital and District education office. Special thanks go to Janet Mbinya and Julius Andove for their laboratory investigations. We thank all staffs and field workers of Mbita Health and Demographic Surveillance System (HDSS) who guided us during our household visits. Gratitude is expressed to Noboru Minakawa, Gabriel O Dida, Carolyn L. Keogh and Richard Culleton for their thoughtful comments and inputs in the development of this manuscript. We deeply appreciate Ayub V. Ofulla for his kind support and arrangement to have former related study reports in study area. We also thank for administrative support from Tomoko Takaya, Hiromi Oda and the staff members of the NUTIM-KEMRI project. This paper is published with the permission of the Directory of KEMRI.

\section{Reference}

1. Nagi S, Chadeka EA, Sunahara T, Mutungi F, Justin YKD, et al. (2014) Risk Factors and Spatial Distribution of Schistosoma mansoni Infection among Primary School Children in Mbita District, Western Kenya. PLoS Negl Trop Dis 8(7): e2991. doi:10.1371/journal.pntd.0002991

Citation: The PLOS Neglected Tropical Diseases Staff (2014) Correction: Risk Factors and Spatial Distribution of Schistosoma mansoni Infection among Primary School Children in Mbita District, Western Kenya. PLoS Negl Trop Dis 8(8): e3190. doi:10.1371/journal.pntd.0003190

Published August 28, 2014

Copyright: (C 2014 The PLOS Neglected Tropical Diseases Staff. This is an openaccess article distributed under the terms of the Creative Commons Attribution License, which permits unrestricted use, distribution, and reproduction in any medium, provided the original author and source are credited. 